\title{
SUPPRESSION OF THE SECRETION OF ATRIAL AND BRAIN NATRIURETIC PEPTIDE AFTER TOTAL CAVOPULMONARY CONNECTION
}

Naoki Yoshimura, MD

Masahiro Yamaguchi, MD

Yoshihiro Oshima, MD

Shigeteru Oka, MD

Yoshio Ootaki, MD

Tomomi Hasegawa, MD

Chikashi Shimazu, MD
Objectives: Among the modifications of the Fontan operation currently being used, total cavopulmonary connection offers the greatest potential for optimizing early and long-term postoperative outcomes. Although studies have established that abrupt increases in right atrial pressure elevate the plasma atrial natriuretic peptide level after the Fontan procedure, changes in plasma natriuretic peptide levels after total cavopulmonary connection have not been clarified. Our hypothesis is that secretion of atrial natriuretic peptide may be suppressed in patients undergoing total cavopulmonary connection because the atrium continues to function at low pressure in those patients. In this study, we measured plasma levels of atrial and brain natriuretic peptide before and during the postoperative period in patients undergoing total cavopulmonary connection.

Methods: We evaluated 60 patients: 30 patients underwent total cavopulmonary connection and 30 patients underwent definitive repair for Fallot's tetralogy. Blood samples for measurement of atrial and brain natriuretic peptide were obtained before the operation and in the postoperative period.

Results: Plasma levels of atrial and brain natriuretic peptide were significantly lower during the early postoperative period in patients undergoing total cavopulmonary connection than in patients undergoing definitive repair for Fallot's tetralogy. No correlations were identified between the atrial natriuretic peptide levels and central venous pressure after total cavopulmonary connection.

Conclusion: These results suggest that total cavopulmonary connection attenuates the secretion of atrial and brain natriuretic peptide in the early postoperative period. The suppressed release of atrial and brain natriuretic peptide after total cavopulmonary connection may have clinical importance. ( $\mathrm{J}$ Thorac Cardiovasc Surg 2000;120:764-9)
S ince Fontan and Baudet ${ }^{1}$ first described their technique for correcting tricuspid atresia in 1971, the original or modified Fontan operation has been widely used to correct various heart defects in patients not able

From the Department of Cardiothoracic Surgery, Kobe Children's Hospital, Kobe, Japan.

Received for publication Dec 29, 1999; revisions requested March 16, 2000; revisions received April 13, 2000; accepted for publication May 15, 2000.

Address for reprints: Naoki Yoshimura, MD, Department of Cardiothoracic Surgery, Kobe Children's Hospital, 1-1-1, Takakura-dai, Suma-ku, Kobe, 654-0081 Japan (E-mail: ynaoki@za2.so-net.ne.jp).

Copyright () 2000 by The American Association for Thoracic Surgery

$0022-5223 / 2000 \$ 12.00+0 \quad \mathbf{1 2 / 1 / 1 0 8 5 9 5}$

doi: $10.1067 / \mathrm{mtc} .2000 .108595$ to undergo anatomic correction. Among the later modifications of the Fontan operation, a significant alteration was introduced by de Leval and associates ${ }^{2}$ when they described total cavopulmonary connection (TCPC). This technique offers many advantages that theoretically reduce the risk of early and long-term complications caused by an enlarged right atrium. ${ }^{3}$

Natriuretic peptide is a peptide with cyclically formed amino acid residues and has several biologic effects: natriuresis and diuresis, vasodilation, suppression of renin, and aldosterone secretion. ${ }^{4}$ Atrial natriuretic peptide (ANP) is secreted mainly from atrial muscle, with the major stimulus being atrial stretch, and brain natriuretic peptide (BNP) is secreted from the ventricular muscles., 5 Although studies have established that abrupt increases in right atrial pressure result in the ele- 

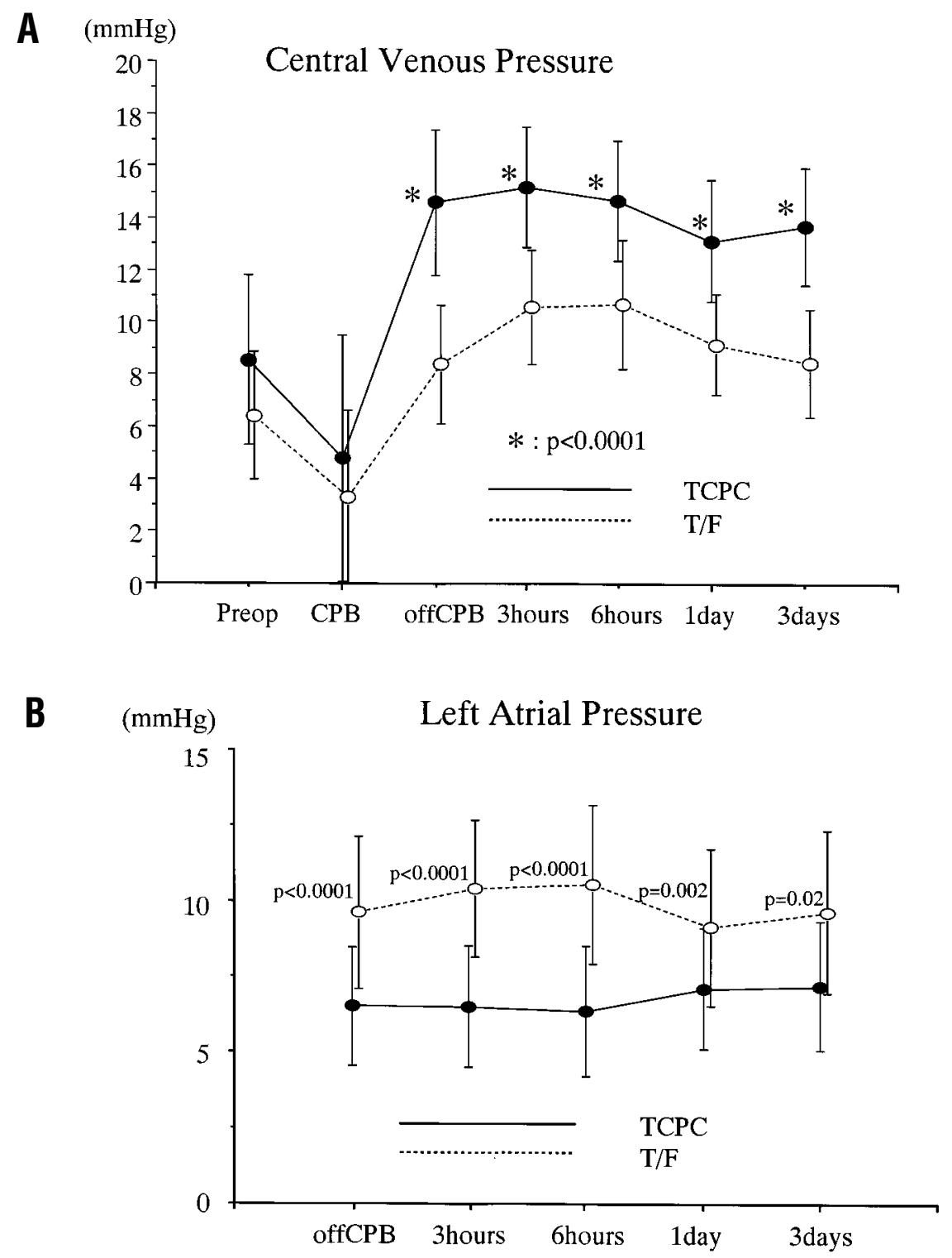

Fig 1. Plots show central venous pressure $(\mathbf{A})$ and left atrial pressure (B) during the study protocol in patients undergoing TCPC (solid line) and in patients undergoing definitive repair for tetralogy of Fallot $(T / F)$.

vation of the plasma ANP level after the Fontan procedure, ${ }^{7-9}$ changes in plasma natriuretic peptide levels after TCPC have not been clarified. Our hypothesis is that ANP secretion may be suppressed in patients undergoing TCPC because the atrium continues to function at a low pressure in those patients. Therefore, to determine whether the TCPC attenuates natriuretic peptide secretion in the early postoperative period, we measured plasma levels of ANP and BNP before the operation and during the postoperative period in patients who underwent TCPC.

\section{Patients and methods}

Study population. Thirty patients undergoing TCPC were studied. Mean age at operation was $7.1 \pm 3.2$ years, ranging from 1 to 18 years, and mean body weight was $19.6 \pm 7.2 \mathrm{~kg}$, ranging from 10.6 to $47.5 \mathrm{~kg}$. Diagnoses included univentricular heart $(n=14)$, tricuspid atresia $(n=5)$, double-outlet right ventricle $(n=5)$, mitral atresia $(n=3)$, pulmonary atresia with intact ventricular septum $(\mathrm{n}=2)$, and pulmonary atresia with ventricular septal defect $(n=1)$. All patients had previously undergone cardiac surgery: 30 Blalock-Taussig shunts in 20 patients, pulmonary artery banding in 8 , a Glenn shunt in 3 , subclavian flap aortoplasty in 3 , atrial septectomy 


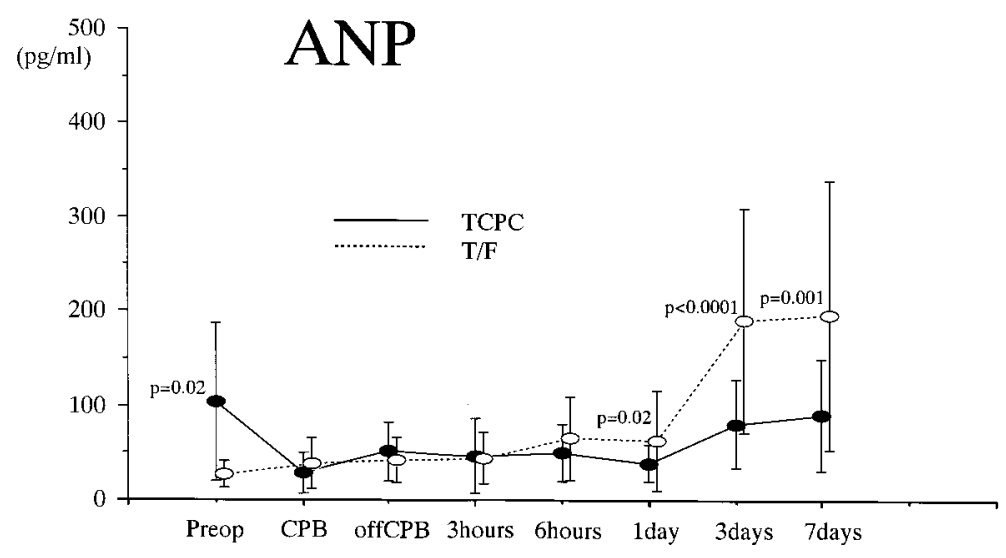

Fig 2. Plasma ANP levels during the study protocol.

in 2, release of pulmonary venous obstruction in 2, pulmonary valvotomy in 1 , and right atrial-right ventricular anastomosis in 1. An extracardiac TCPC was performed in 20 patients, and intra-atrial conduit TCPC was performed in 10 others. A 16- to 22-mm expanded polytetrafluoroethylene tube graft was interposed between the inferior vena cava and pulmonary artery in all but 1 patient, who underwent extracardiac TCPC with direct anastomosis between the pulmonary trunk and the inferior vena cava. If necessary, the atrial septal defect was enlarged so as not to disturb the pulmonary venous return. Unless a concomitant intracardiac procedure was to be performed, aortic crossclamping was avoided. Every effort was made to minimize the duration of cardiopulmonary bypass (CPB). Two patients underwent the entire operation without $\mathrm{CPB}$.

For comparison with the TCPC group, 30 patients who were undergoing definitive repair for Fallot's tetralogy were studied. Their mean age at operation was $5.9 \pm 2.5$ years, ranging from 1 to 13 years, and mean body weight was 17.8 $\pm 5.5 \mathrm{~kg}$, ranging from 10.5 to $38.8 \mathrm{~kg}$. Fourteen patients had previously undergone a Blalock-Taussig shunt operation.

In all patients, an arterial line for continuous blood pressure monitoring and blood sampling and a central venous line for central venous pressure monitoring were placed. Additionally, a $2 \mathrm{~F}$ catheter was inserted into the left atrium for pressure tracings. If necessary, dopamine $\left(3-15 \mu \mathrm{g} \cdot \mathrm{kg}^{-1}\right.$ $\cdot \min ^{-1}$ ), dobutamine (3 to $\left.10 \mu \mathrm{g} \cdot \mathrm{kg}^{-1} \cdot \mathrm{min}^{-1}\right)$ ), or epinephrine $\left(0.025\right.$ to $\left.0.2 \mu \mathrm{g} \cdot \mathrm{kg}^{-1} \cdot \mathrm{min}^{-1}\right)$ was used as an inotropic agent. Informed consent was obtained from each participating patient.

Study protocol and measurements of natriuretic peptides. Plasma ANP and BNP concentrations and hemodynamic parameters were measured at 8 points during the study protocol as follows: (1) after induction of anesthesia and before skin incision, (2) during CPB (except in the 2 patients who underwent TCPC without CPB), (3) immediately after discontinuation of CPB (or immediately after establishment of the Fontan circulation in the 2 patients without CPB), (4) 3 hours after $\mathrm{CPB},(5) 6$ hours after $\mathrm{CPB},(6)$ on the first post- operative day, (7) on the third postoperative day, and (8) on the seventh postoperative day. Blood samples were collected via a radial arterial line during the first 3 days after the operation and were obtained by venipuncture on the seventh postoperative day. Each blood specimen was collected in a chilled tube containing $4.5 \mathrm{mg}$ of sodium ethylenediaminetetraacetic acid and 1500 units of aprotinin. The blood sample was centrifuged immediately, and the plasma was frozen and stored until hormone assay was performed. Concentrations of plasma ANP and BNP were measured by a commercially available specific radioimmunoassay system (SRL, Tokyo, Japan). The concentrations of ANP and BNP were expressed in picograms per milliliter, and their normal ranges were less than $40 \mathrm{pg} / \mathrm{mL}$ and $20 \mathrm{pg} / \mathrm{mL}$, respectively.

Statistical analysis. All values are expressed as mean \pm standard deviation. The differences from control patients were determined by factorial analysis of variance. When a significant difference was detected, the Scheffé multiple range test was applied.

\section{Results}

Operative mortality and morbidity. Two early deaths occurred in the TCPC group. The first patient died of low cardiac output syndrome caused by pulmonary artery thrombosis. The second death was in a patient with a severely unbalanced pulmonary artery. This patient died of ventricular tachyarrhythmia on postoperative day 3. Inhaled nitric oxide was administered to 17 patients with critical pulmonary perfusion. Six patients required thoracocentesis for persistence of pleural or pericardial effusions for more than 2 weeks. No perioperative deaths or critical complications occurred in the group with tetralogy of Fallot.

Hemodynamic parameters. No differences were detected in heart rate and blood pressure between the 2 groups during the study protocol. Before the operation, central venous pressure in patients who underwent 


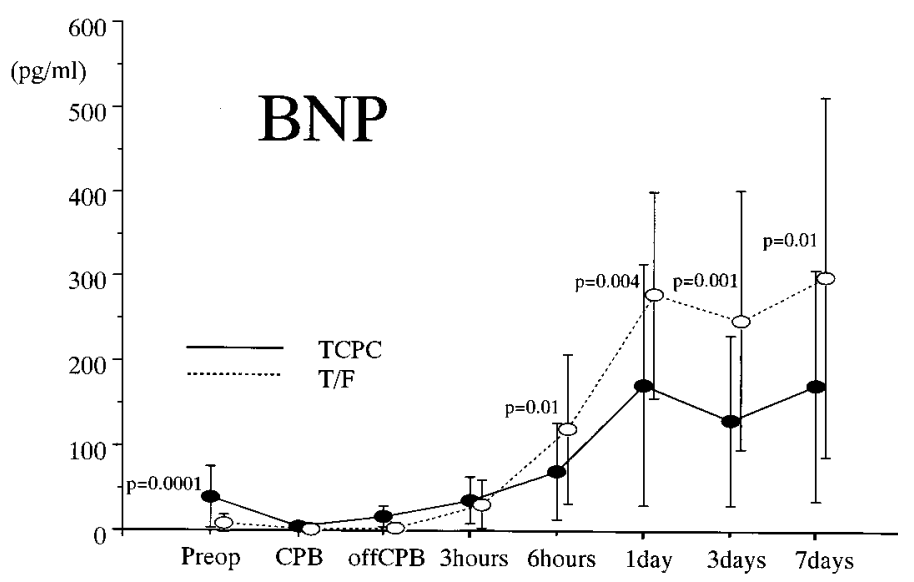

Fig 3. Plasma BNP levels during the study protocol.

TCPC was slightly higher than that in patients who underwent definitive repair for Fallot's tetralogy. Central venous pressure increased in the TCPC group soon after establishment of the Fontan circulation and remained at the same levels thereafter. No significant change in central venous pressure was noted in patients with Fallot's tetralogy during the perioperative course. Central venous pressure differed significantly between the 2 groups at every postoperative point (Fig 1, $A$ ), and mean left atrial pressure was lower for the TCPC group than for the tetralogy of Fallot group at every postoperative interval (Fig 1, B).

Plasma ANP and BNP concentrations. Time courses of plasma ANP and BNP levels during the study protocol are shown in Figs 2 and 3, respectively. The plasma ANP level before the operation was significantly higher in the TCPC group than in the tetralogy of Fallot group. ANP concentration increased 3-fold in the Fallot's tetralogy group 3 days after the operation. Plasma ANP levels were significantly lower at 1, 3, and 7 days after the operation in the TCPC group than in the tetralogy of Fallot group (Fig 2). Plasma BNP levels before the operation were significantly higher in the TCPC group than in the group with tetralogy of Fallot. The plasma BNP levels increased abruptly after the operation in patients with Fallot's tetralogy, as well as in patients who underwent TCPC, but were significantly lower in patients who underwent TCPC (Fig 3). Perioperative ANP and BNP levels in 2 patients who underwent TCPC without CPB were not different from those in the patients who underwent TCPC with CPB.

\section{Discussion}

The heart functions not only as a pump, but also as an important endocrine organ that secretes 2 natriuretic peptides. ${ }^{4}$ One is ANP, primarily derived from the atrium with the major stimuli being atrial stretch and elevation of intra-atrial pressure. The other is BNP, which is synthesized and secreted by the ventricles. ANP has multiple biologic actions including natriuresis, diuresis, vasodilation of the systemic and pulmonary arteries, and inhibition of the secretion of aldosterone. BNP plays an important role in regulating somatic fluid and blood pressure. ${ }^{5,6}$ The plasma concentrations of ANP and BNP are markedly elevated in patients with congestive heart failure in proportion to the severity of the disease..$^{5}$ Although many reports have examined plasma ANP and BNP concentrations in chronic heart failure, ${ }^{5,6}$ few have explored the changes in plasma natriuretic peptide concentrations during and after various cardiac operations. ${ }^{10-13}$ Moreover, the period during and after corrective operations for congenital heart disease in children is characterized by a complex pathophysiologic condition with diminished performance of the myocardium, increased capillary permeability, and disturbed volume homeostasis. ${ }^{14-17}$ Only very limited data exist regarding the role of the natriuretic peptide family in such patients. Pfenninger and associates, ${ }^{15}$ who studied 22 children with various types of congenital heart disease, concluded that plasma ANP concentrations are increased after cardiac surgery in children and that this increase is moderately correlated with the blood volume status of the patient. Stewart and associates $^{7,8}$ measured plasma levels of ANP in children undergoing the Fontan operation (atriopulmonary anastomosis) and concluded that the Fontan anastomosis resulted in a drastic increase in plasma ANP levels because of right atrial stretch. Hiramatsu and associates $^{9}$ also reported that abrupt increases in right atrial pressure after the Fontan operation had been associated 
with extreme elevations in plasma levels of ANP, with a positive, statistically significant correlation between central venous pressure and plasma ANP levels.

Our study reveals 3 main findings. First, plasma ANP levels were significantly lower during the early postoperative period in the TCPC group than in the group with tetralogy of Fallot. Second, no correlation was identified between the ANP levels and central venous pressure after TCPC, suggesting that the secretion of ANP was suppressed in patients undergoing TCPC. Third, postoperative plasma BNP concentrations changed to a lesser degree in patients who underwent TCPC compared with those in patients with Fallot's tetralogy.

We hypothesized that TCPC with an extracardiac or intra-atrial conduit attenuates ANP secretion because all parts of the atrium continue to function at a low pressure in those patients. Although the central venous pressure increased after establishment of the Fontan circulation, there was no concomitant increase in atrial pressure or atrial distention in patients who underwent extracardiac or intra-atrial conduit TCPC. Burch and associates ${ }^{18}$ measured plasma ANP levels in 3 children undergoing TCPC and reported that the ability to release ANP into the circulation was impaired after TCPC compared with that after the Fontan procedure. They also stated that the impaired release of ANP might result in retention of salt and water after TCPC. Recently, human ANP has been produced commercially by a genetic recombinant technique (Suntory; Osaka, Japan). Hiramatsu and associates ${ }^{9}$ examined the effects of human ANP on hemodynamic parameters after the Fontan procedure and concluded that human ANP could be a physiologic diuretic and a pulmonary vasodilator after this procedure. The administration of human ANP should offer the possibility of combining the hemodynamic benefits of TCPC with the endocrine benefits of the Fontan procedure.

Although previous studies have shown changes in plasma ANP concentrations associated with cardiac surgery, ${ }^{7-18}$ the effects of cardiac surgery with CPB on plasma BNP concentrations have not yet been clarified. Morimoto and associates ${ }^{19}$ examined plasma concentrations of BNP during the perioperative period in adult patients undergoing cardiac surgery. They concluded that the plasma BNP concentrations became markedly and abruptly elevated after CPB and reflected the state of left ventricular function. Ationu and associates ${ }^{20}$ had measured plasma BNP concentrations in 9 children undergoing cardiac surgery with $\mathrm{CPB}$ and concluded that the major source of plasma BNP in patients with congenital heart defects is the cardiac ventricle. In the present study, plasma BNP levels increased abruptly after cessation of CPB in patients with Fallot's tetralogy, as well as in patients undergoing TCPC. This result was in accord with that of Morimoto and associates. ${ }^{19}$ However, plasma BNP concentrations were significantly lower in the TCPC group than in the group with Fallot's tetralogy. BNP is secreted mainly from the left ventricle and its secretion increases in proportion to the severity of the ventricular dysfunction. ${ }^{6}$ Ikeda and colleagues ${ }^{21}$ reported that secretion of BNP is stimulated by the increase of left ventricular end-systolic wall stress in patients with aortic stenosis. Hayabuchi, Matsuoka, and Kuroda ${ }^{22}$ studied 14 patients with surgically repaired Fallot's tetralogy and concluded that the BNP concentration reflects right ventricular pressure and volume overload. We are uncertain why plasma BNP levels were lower in patients undergoing TCPC than those in patients with Fallot's tetralogy. The probable reason is that the TCPC procedure offers the considerable advantage of lowering the ventricular volume load in the immediate postoperative period, ${ }^{23}$ which would result in the suppression of BNP secretion, whereas the volume overload of both ventricles increases immediately after repair for Fallot's tetralogy. ${ }^{24}$ The suddenly increased loading in both ventricles may be partly compensated for by the increase of BNP secretion.

Limitation of the present study. The limitation of the present study was that underlying heart conditions differed between the 2 groups. The group with Fallot's tetralogy was used as a control group to compare the postoperative changes in plasma ANP and BNP concentrations. Taking into consideration the multiple factors that may affect ANP and BNP levels, a group of patients who underwent the original or modified Fontan operation (atriopulmonary anastomosis) would have been more suitable as a control group, but such a group would have been extremely difficult to incorporate into the study, because we currently use TCPC as the procedure of choice. ${ }^{3}$

The patients in the TCPC group had higher plasma levels of ANP and BNP than the Fallot's tetralogy group before the operation. The probable reason is the wide spectrum of underlying heart disease and its severity in patients who underwent TCPC. Several patients in the TCPC group had high ANP and BNP levels before the operation; these patients might have been in more serious condition than the patients with Fallot's tetralogy. Nevertheless, after the operation those levels became lower in the TCPC group. Stewart and associates ${ }^{7,8}$ reported that plasma ANP levels increased in excess of $300 \mathrm{pg} / \mathrm{mL}$ after establishment of atriopulmonary anastomosis in patients undergoing 
the Fontan procedure. On the other hand, plasma ANP levels remained in the range between 50 and 100 $\mathrm{pg} / \mathrm{mL}$ in our series of patients having TCPC. These results suggested that the ability to release ANP and BNP into the circulation is suppressed after TCPC.

\section{Conclusion}

We measured plasma levels of ANP and BNP before the operation and during the postoperative period in patients who were undergoing TCPC. These results were compared with those in patients with Fallot's tetralogy. Plasma ANP levels were significantly lower during the early postoperative period in the TCPC group than in the Fallot's tetralogy group, and there was no correlation between the ANP levels and central venous pressure after TCPC. Postoperative plasma BNP concentrations also changed to lower levels in patients who underwent TCPC than in those with Fallot's tetralogy. Despite several limitations of our study as a clinical approach, we have demonstrated that TCPC attenuates ANP and BNP secretion in the early postoperative period. The suppressed release of ANP and BNP after TCPC may have clinical importance.

\section{REFERENCES}

1. Fontan F, Baudet E. Surgical repair of tricuspid atresia. Thorax 1971;26:240-8

2. de Leval MR, Kilner P, Gewillig M, Bull C. Total cavopulmonary connection: a logical alternative to atriopulmonary connection for complex Fontan operations. J Thorac Cardiovasc Surg 1988;96:682-95.

3. Yoshimura N, Yamaguchi M, Ohashi H, Oshima Y, Toyoda Y, Ogawa K. Conversion of right atrioventricular to total cavopulmonary anastomosis in the management of post-Fontan arrhythmia: report of a case. Surg Today 1999;29:284-7.

4. Needleman P, Greenwald JE. Atriopeptin: a cardiac hormone intimately involved in fluid, electrolyte, and blood-pressure homeostasis. N Engl J Med 1986;314:828-34.

5. Yoshimura M, Yasue H, Okumura K, Ogawa H, Jougasaka M, Mukoyama M, et al. Different secretion patterns of atrial natriuretic peptide and brain natriuretic peptide in patients with congestive heart failure. Circulation 1993;87:464-9.

6. Yasue H, Yoshimura M, Sumida H, Kikuta K, Kugiyama K, Jougasaka $\mathrm{M}$, et al. Localization and mechanism of secretion of B-type natriuretic peptide in comparison with those of A-type natriuretic peptide in normal subjects and patients with heart failure. Circulation 1994;90:195-203.

7. Stewart JM, Seligman KP, Zeballos G, Romano A, Clarke BJ, Woolf PK, et al. Elevated atrial natriuretic peptide after the Fontan procedure. Circulation 1987;76(Suppl):III-77-82.

8. Stewart JM, Gewitz MH, Clark BJ, Seligman KP, Romano A, Zeballos GA, et al. The role of vasopressin and atrial natriuretic factor in postoperative fluid retention after the Fontan procedure. J Thorac Cardiovasc Surg 1991;102:821-9.

9. Hiramatsu T, Imai Y, Takanashi Y, Seo K, Terada M, Nakazawa
M. Hemodynamic effects of human atrial natriuretic peptide after modified Fontan procedure. Ann Thorac Surg 1998;65:761-4.

10. Nishimura K, Saito Y, Hidaka T, Ishihara T, Nakao K, Imura H, et al. Does atrial appendectomy aggravate secretory function of atrial natriuretic polypeptide? J Thorac Cardiovasc Surg 1991;101:502-8

11. Kim KB, Lee CH, Kim CH, Cha YJ. Effect of the Cox maze procedure on the secretion of atrial natriuretic peptide. J Thorac Cardiovasc Surg 1998;115:139-47.

12. Yoshihara F, Nishikimi T, Kosakai Y, Isobe F, Matsuoka H, Takishita $\mathrm{S}$, et al. Atrial natriuretic peptide secretion and body fluid balance after bilateral atrial appendectomy by the maze procedure. J Thorac Cardiovasc Surg 1998;116:213-9.

13. Jahnke AW, Leyh R, Bernhard A, Sievers HH. Atrial natriuretic peptide release at rest and with exercise after cardiac transplantation with bicaval anastomosis. J Thorac Cardiovasc Surg 1995;110:1600-5.

14. Girardin EP, Berner ME, Favre HR, Oberhaensli I, Rouge JC, Friedli B, et al. Atrial natriuretic factor after heart operations in children: relation to hemodynamic and renal parameters. J Thorac Cardiovasc Surg 1991;102:526-31.

15. Pfenninger J, Shaw S, Ferrari P, Weidmann P. Atrial natriuretic factor after cardiac surgery with cardiopulmonary bypass in children. Crit Care Med 1991;19:1497-502.

16. Agnoletti G, Scotti C, Panzali AF, Ceconi C, Curello S, Alfieri O, et al. Plasma levels of atrial natriuretic factor (ANF) and urinary excretion of ANF, arginine vasopressin and catecholamines in children with congenital heart disease: effect of cardiac surgery. Eur J Cardiothorac Surg 1993;7:533-9.

17. Ivy DD, Kinsella JP, Wolfe RR, Abman SH. Atrial natriuretic peptide and nitric oxide in children with pulmonary hypertension after surgical repair of congenital heart disease. Am J Cardiol 1996;77:102-5.

18. Burch M, Shinebourne EA, Rigby ML, Carter N, Jeffery S, Stanley P, et al. Plasma atrial natriuretic peptide after the Fontan procedure and total cavopulmonary connexion. Int $\mathrm{J}$ Cardiol 1990;27:161-5.

19. Morimoto K, Mori T, Ishiguro S, Matsuda N, Hara Y, Kuroda H. Perioperative changes in plasma brain natriuretic peptide concentrations in patients undergoing cardiac surgery. Surg Today 1998;28:23-9.

20. Ationu A, Singer DRJ, Smith A, Elliott M, Burch M, Carter ND. Studies of cardiopulmonary bypass in children: implications for the regulation of brain natriuretic peptide. Cardiovasc Res 1993;27:1538-41.

21. Ikeda T, Matsuda K, Itoh H, Shirakami G, Miyamoto Y, Yoshimasa T, et al. Plasma levels of brain and atrial natriuretic peptides elevate in proportion to left ventricular end-systolic wall stress in patients with aortic stenosis. Am Heart J 1997; 133:307-14

22. Hayabuchi Y, Matsuoka S, Kuroda Y. Plasma concentrations of atrial and brain natriuretic peptides and cyclic guanosine monophosphate in response to dobutamine infusion in patients with surgically repaired tetralogy of Fallot. Pediatr Cardiol 1999;20:343-50

23. Petrossian E, Reddy VM, McElhinney DB, Akkersdijk GP, Moore P, Parry AJ, et al. Early results of the extracardiac conduit Fontan operation. J Thorac Cardiovasc Surg 1999;117:688-96.

24. Kurosawa H, Morita K, Yamagishi M, Shimizu S, Becker AE, Anderson RH. Conotruncal repair for tetralogy of Fallot: midterm results. J Thorac Cardiovasc Surg 1998;115:351-60. 